\title{
Bermuda Sidecars: Supervising Reinsurance Companies in Innovative Global Markets"
}

\author{
Marcelo Ramella ${ }^{\mathrm{a}}$ and Leila Madeiros ${ }^{\mathrm{b}}$ \\ ${ }^{a}$ Policy and Research Department, Bermuda Monetary Authority, BMA House, 43 Victoria Street, \\ Hamilton HM 12, Bermuda. \\ E-mail: mramella@bma.bm \\ ${ }^{\mathrm{b}}$ Association of Bermuda Insurers and Reinsurers (ABIR), XL House, 1 Bermudiana Road, Hamilton HM \\ 11, Bermuda. \\ E-mail: leila.madeiros@abir.bm
}

The paper looks at the phenomenon of reinsurance sidecars, as an example of innovation in cross-sectoral risk transfer between the insurance and the capital markets. It explores the emergence, unfolding and retreat of sidecars in Bermuda with the goal of identifying and establishing key issues shaping how supervisors make sense and act upon innovative industry practices. The paper describes key market and industry features setting the scene for the emergence of sidecars, reviews the literature on sidecars, discusses supervisory challenges sidecars present and explores avenues for addressing these challenges. The paper argues that sidecars offer a fertile ground for better understanding the relationship between industry and supervisors in a context of innovation taking place in a rapidly changing landscape, populated by global players.

The Geneva Papers (2007) 32, 345-363. doi:10.1057/palgrave.gpp.2510130

Keywords: Bermuda; innovation; reinsurance supervision; risk-transfer; sidecars

\section{Introduction}

Is financial supervision keeping up with the pace of innovation and change in the industry? The answer, I believe, is "yes." Risk management and the supervisory system cannot and should not evolve independently of each other. Indeed, the constructive dialogue underway today between supervisory agencies and financial services providers is helping to create a "virtuous circle": the supervisory framework is becoming more closely aligned with the best risk management practices in use, while at the same time encouraging further advances in those practices. ${ }^{1}$

Jaime Caruana's confidence in the productive collaboration between the financial services industry and supervisors appears to underpin his belief that the latter are both

\footnotetext{
* The views expressed in this paper are the authors' own and do not necessarily reflect the views of the Bermuda Monetary Authority or those of the Association of Bermuda Insurers and Reinsurers or its member organisations.

${ }^{1}$ Caruana (2005, p. 11).
} 
absorbing and shaping the innovation taking place in the former. Cross-sectoral risk transfer is one such example, as evidenced by the quantitative expansion of business as well as the qualitative growth in products and services. Moreover, this seems to be occurring at a speed not previously experienced. On the other hand, as quantity, quality and velocity of innovation generate new scenarios, so new concerns emerge.

This paper looks at the phenomenon of reinsurance sidecars, as an example of innovation in cross-sectoral risk transfer between the reinsurance and the capital markets. It argues that sidecars offer a fertile ground for better understanding the relationship between industry and supervisors in a context of innovation taking place in a rapidly changing landscape, populated by global players. In particular, it explores the emergence, unfolding and retreat of sidecars in Bermuda with the goal of identifying and establishing key issues shaping how supervisors make sense of, and act upon, innovative industry practices.

The paper is organised as follows. The following section describes key market and industry features setting the scene for the emergence of reinsurance sidecars. The next section looks at the existing literature on sidecars, providing an account of the perspective of the insurance industry on what sidecars are, how they operate and what makes them different from other insurance undertakings. The penultimate section revisits sidecars, from the perspective of the insurance supervisor, looking at the supervisory challenges they present and exploring avenues for addressing these. Finally, the last section concludes the paper, proposing some learning points that can be drawn from the phenomenon of sidecars, especially with respect to supervising rapidly occurring innovations and the relationship between innovation and financial stability.

\section{Setting the scene for the emergence of sidecars}

The insurance and reinsurance industry is described as being cyclical with respect to pricing. According to Enz, "price fluctuations can originate from the supply side or from the demand side. In the case of reinsurance, the supply side is dominant. In years with equity growth, low claims and high investment income, the supply of reinsurance capacity expands, prices fall.". On the other hand, "shrinking equity, low returns on investment and catastrophic losses cause prices to rise.",

The year 2005 proved to be a record one with respect to catastrophic losses. ${ }^{4}$ Estimates of 2005 worldwide insured property cat losses have been at $\$ 83.4$ billion, with between $\$ 72.6$ and 79 billion occurring in North America. ${ }^{5}$ Putting this latter figure in perspective, the 2004 United States hurricane season or the 2001 terrorism attacks, generated losses of just under $\$ 30$ billion each. Further, in 1992, losses to hurricane Andrew amounted to in excess of $\$ 20$ billion. $^{6}$ Moreover, as a result of the 2005 storms, according to Standard and Poor's, "specialized property catastrophe

\footnotetext{
${ }^{2}$ Enz (2002, p. 6).

${ }^{3}$ Ibid.

${ }^{4}$ A.M. Best (2006a).

${ }^{5}$ Guy Carpenter (2006b).

${ }^{6}$ Benfield (2006a).
} 
players lost between 40 to 100 per cent of their June 2005 capital base with the storms and the equivalent of many years earnings."7

These record losses, and especially the emerging discrepancies between the modelbased estimates and the actual loss verified, generated a review of the modelling tools used by industry. The review of models included the assumptions on which models operate, considerations on frequency and severity of events, the kind of data used, inter-dependencies built into the models as well as other external factors (e.g. demand surge). ${ }^{8}$ The review of modelling tools used by cat insurers impacted on, among other things, the risk management approach adopted by both the modellers and users. ${ }^{9}$ A key element emerging from the model review exercise was the upward revision of the estimated capital needed to adequately cover certain cat exposures.

Similarly, after the 2005 hurricane season, the major rating agencies made changes in 'their approaches for evaluating companies' capital adequacy and risk management processes and controls" which included raising capital requirements of insurers taking on certain cat risks. ${ }^{10}$ In addition, rating agencies revisited their overall methodologies with respect to the assessment of catastrophic events. ${ }^{11}$

To summarise, the combined effect of record losses, capital erosion, model reviews and rating agencies' reassessments contributed to uncertainty with respect to availability of reinsurance capacity. Very importantly, uncertainty affected both the amount and the timing of available capacity; this, in turn, exercised a determinant effect on pricing. ${ }^{12}$

\section{Sidecars - a brief review of the literature}

So far, we have focused on identifying some key elements that help us better understand the market conditions in which insurers and reinsurers found themselves at the end of 2005, when the first reports of sidecar formations appeared. However, we have still to provide the reader with a conceptualisation of the term sidecar. What are sidecars? Are sidecars any different from other reinsurance undertakings? If so, to what extent is this the case? What elements may help understand the distinctive features of a sidecar?

This section aims to address these points, looking at sidecars with a specific focus on elements that are of interest to regulators and supervisors. The paragraphs that follow discuss literature on sidecars published between September 2005 and March 2007. Literature searches were carried out primarily via the Business Source Premier service of the EBSCOhost ${ }^{13}$ database. In particular, the issue of sidecars appears addressed in

${ }^{7}$ Standard and Poor's (2006, p. 13).

${ }^{8}$ Risk Management Solutions (2005).

${ }^{9}$ Benfield (2006a).

${ }^{10}$ Guy Carpenter (2006a, p. 1).

${ }^{11}$ International Association of Insurance Supervisors (2006).

12 Benfield (2006a); Guy Carpenter (2006c).

${ }^{13}$ Business Source Premier is a business research database, providing full text for more than 2,300 journals, including full text for more than 1,100 peer-reviewed titles. Business Source Premier provides full text coverage in disciplines of business, including marketing, management, MIS, POM, accounting, finance and economics. For details on Business Source Premier, please visit http://web.ebscohost.com. 
three broad types of sources, that is, insurance industry literature, investment industry literature and rating agency literature.

We order the findings from the literature review into three broad themes addressed in the following three sections: "The players", "The transactions binding the players" and "The players and their drives."

\section{The players}

As a first step towards shedding light on sidecars, we identify the players taking part in a sidecar. The literature identifies four broad types of key players, as follows: the sidecar itself, the sidecar sponsor, the investors in the sidecar and the sidecar service providers. Let us look at them, focusing on identifying defining traits in the players that make them any different from players taking part in more traditional insurance undertakings.

The first player to identify is the sidecar itself. Sidecars are, according to the literature, reinsurance companies. To a large extent, sidecars are by no means different from other reinsurance companies. According to rating agency Moody's, for example, sidecars "much like traditional reinsurers, are established to assume underwriting risk from ceding insurers or reinsurers." 14

Sidecars appear defined not as any kind of reinsurance company but as a special type of it. What makes a sidecar different from other reinsurance companies are constraints placed along the vectors of capacity and time. For example, the IMF understands sidecars to be "a limited-purpose reinsurance vehicle with a finite life."15 On the same vein, following reinsurance industry specialist Benfield, "a sidecar is a limited-life special purpose entity." 16 Rating agency A.M. Best goes further than the IMF or Benfield and defines sidecars as Special Purpose Vehicles, "a sidecar is set up as a special-purpose vehicle (SPV) with a defined purpose and a limited lifetime."17 However, and importantly, these purpose and time constraints do not appear to be a trait unique to sidecars. For example, companies issuing Cat Bonds also possess these characteristics. $^{18}$

The second player identified in the literature is the sidecar sponsor, that is, the organisation or organisations championing the sidecar. According to reinsurance industry specialist Guy Carpenter, "a sidecar is a specially formed reinsurance company that attaches itself to an existing sponsoring (re)insurer to provide capacity. ... The sidecar carrier has no stated interest in writing other business, seeking a financial strength rating, or building other business relationships. The sponsoring (re)insurer will cede business to the sidecar." 19 For a sidecar, a sponsor is another insurance or reinsurance company that plays the part of the client that buys coverage from it, often in the form of retrocession. Moreover, the sponsor is the sole client of

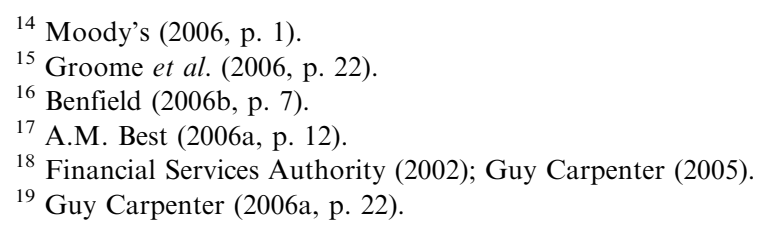


the sidecar. A.M. Best goes further and argues that sidecars selling insurance coverage to clients other than the sponsor are not "true sidecars." ${ }^{20}$ Guy Carpenter also follows this narrow understanding of a sidecar. ${ }^{21}$ This position however, does not appear to be shared by the investment industry literature. For example, Hertz and McGuiness ${ }^{22}$ break down sidecars by whether they are "market facing or not", the latter having a single client, that is, the sponsor, and the former writing business for third-party clients.

The role of the sponsor seems to go beyond that of the client. For example, following rating agency Standard and Poor's, "the sponsoring reinsurer is generally responsible for all aspects of underwriting and claims settlements and receives a management fee that is generally tied to the profitability of the sidecar." 23 This view is shared by others. ${ }^{24}$

Investors in the sidecar are the third key player in understanding a sidecar arrangement. For the International Association of Insurance Supervisors for example, "Sidecar arrangements provide for the transfer of risk from insurance companies to capital markets by enabling capital market institutions and their clients to underwrite particular risks directly." 25 Further, investors in sidecars appear to be not any type of investors but capital market players with a high-risk appetite. According to investment industry publication Investment Dealers' Digest (IDD), "sidecars, an emerging investment vehicle designed to share in the peaks and valleys of catastrophe insurance, are quickly emerging as a top choice for risk-tolerant investors." 26 Moreover, IDD identifies three such high-risk categories: hedge funds, investment banks and private equity funds.

Investors in sidecars, however, do not appear to be different from investors in other insurance or reinsurance companies or financial products. For example, high risk taking private equity funds, ${ }^{27}$ as well as hedge funds, ${ }^{28}$ were significant investors in the new start-ups that followed the re-capitalisation of the reinsurance market after hurricane Katrina in just the same way as occurred with sidecars.

The last group of players involved in the sidecar are the service providers. Sidecars operate as companies with no dedicated staff, outsourcing all their functions. ${ }^{29}$ As such, and in addition to the underwriting services provided by the sponsors discussed above, sidecars purchase among other things: company management services, claim management services, actuarial services, investment management services and legal counsel services. Again, as in the case of investors, the outsourcing of services by entities without dedicated staff is not a quality unique to sidecars. This characteristic, for example, is a trait that can be found in captive insurance companies. ${ }^{30}$

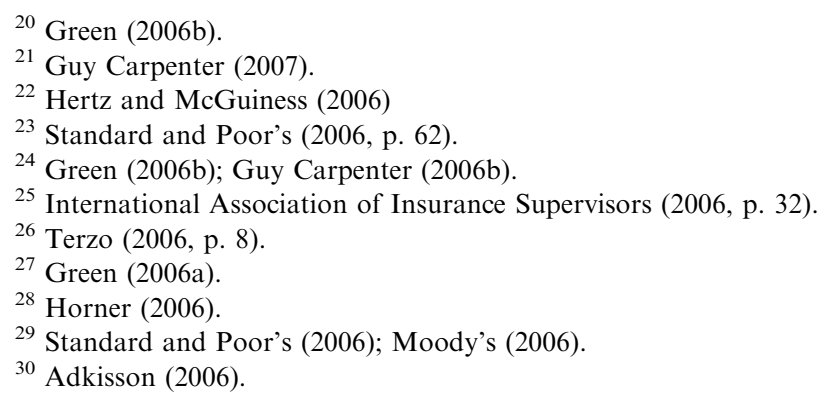


To sum up, from the perspective of the players in the arrangement, sidecars are reinsurance companies with a limited purpose that are funded by high-risk appetite capital markets participants, and are reliant on a sponsor that acts as client as well as underwriter and on a network of other service providers.

\section{The transactions binding the players}

This section looks at the literature on the main transactions binding the players involved in the reinsurance sidecar. First, it looks at the relationship between the sidecar and the sponsor. Second, it explores transactions between the sidecar and the investors. Third, it concentrates on the relationship joining investors, the sidecar and the sponsor. Finally, it looks at additional transactions that sidecars entertain with other players.

We have so far established that, according to the industry literature, between a sidecar and its sponsor there is a relationship that verses on two fronts, the sponsor as a client and as a service provider of the sidecar. Let us look at the first element and explore how the literature makes sense of the client relationship between the sponsor and the sidecar.

Sponsors, as clients of the sidecar, buy coverage protecting them from the risk of catastrophe occurring to the sponsor's property, marine or energy book of business. Industry Loss Warranties and aviation risks also appear mentioned in the literature. ${ }^{31}$ With respect to the geographical location of the risks ceded, these appear to be mostly in the U.S.A., especially in Florida, California and the Gulf of Mexico.

The cession of risks is done mostly under quota-share, and to a lesser extent excessof-loss arrangements. Contracts are of limited duration, usually not longer than three years. Quota-share arrangements are singled out in the literature as an essential trait of sidecars. For example, Lane defines sidecars as "versions of capped quota-shares.",32 Finally, and unique to sidecars, the quota-share agreement appears to be, more often than not, the only contract entered into by the sidecar. ${ }^{33}$ According to rating agency Standard and Poor's, sidecars "will typically enter into a two- to three-year agreement with a sponsoring reinsurer, in which the sidecar will quota share a portion of the reinsurers' book of business. This typically consists of short-tail business such as property, marine, and energy." ${ }^{34}$ Finally, contracts between sidecar and sponsoring reinsurer include fees and commissions related to the procurement as well as the eventual profitability of the business.

In addition, sidecar and sponsor enter into service provision contracts. As we have seen, the sponsor is portrayed not just as a client but also a service provider of the sidecar. In particular, sidecars buy from sponsors underwriting, claims management and general management services. ${ }^{35}$

A second set of transactions are those between the sidecar and its investors. Investors engage in sidecar financing as providers of equity and debt. The provision of

\footnotetext{
31 Sclafane (2007).

32 Lane (2006).

33 Collis (2006).

${ }^{34}$ Standard and Poor's (2006, p. 15).

${ }^{35}$ Collis (2006); Standard and Poor's (2006); Perez (2007).
} 
equity can take the form of common or preferred shares, and is usually done indirectly, via a holding company that owns the 100 per cent of the sidecar. Investors, in turn, buy shares of the holding company. Further, investors acquire these shares in private placements. ${ }^{36}$ With respect to debt financing, this is provided either directly to the sidecar company or indirectly via the holding company. As mentioned above, investors are generally private equity funds, hedge funds and investment banks.

A third set of transactions binds the sidecar, the investors and the sponsor. This relates to the monies provided to the sidecar by the investors and the sponsor and that are set aside in order to provide the sponsor with an additional layer of security with respect to the eventual payment of claims. In short, proceeds of equity and debt investments in sidecars as well as premiums paid to the sidecar are deposited in a trust account that has the sponsor as the beneficiary. The monies in this account collateralise the liabilities emerging from the reinsurance arrangement between the sponsor and the sidecar. Should a claim materialise, the sponsor has privileged accesses to the funds in the collateral trust account. Regarding the mechanisms for establishing the amount of funds available in the collateral trust account, these usually follow the terms of the ceding arrangement. While most sidecars collateralise to full aggregate limits, there are cases of collateralisation calculated to a multiple of the probable maximum loss or to the loss ratio cap. ${ }^{37}$ While the first type provides for full coverage of claims, the second and third types leave the cedent exposed to the possibility that the sidecar may not be able to cover losses in full. In short, the latter two types leave the sponsor with a "tail risk." 38

Finally, we look at transactions binding the sidecar and players other than the sponsor and the investors. Sidecars are, according to Moody's, "automatic" structures. They are made up of a series of arrangements that enable them to come to exist, operate and fulfil their purposes. There are several other players and arrangements, in addition to the ones discussed above, for example, insurance management companies providing general management and claims management services, investment management companies managing assets from the sidecar portfolio and companies providing actuarial services. Figure 1 provides a graphic representation of a sidecar, the sidecar's main players and the transactions binding them.

\section{The players and their drives}

This section looks succinctly at the motivations that the literature has identified as driving the formation of sidecars. We look at these first from the perspective of the sponsor of the sidecar and second from the perspective of the investors in the sidecar.

A key factor driving sponsors into the sidecar idea is the ability to provide additional capacity. As sole client/underwriter of the sidecar's business, sponsors make of the

\footnotetext{
${ }^{36}$ Goldman Sachs (2006).

${ }^{37}$ Perez (2007); A.M. Best (2006b); Collis (2006); Sigma (2006); Wharton Risk Center (2007).

${ }^{38}$ A.M. Best (2006b).
} 


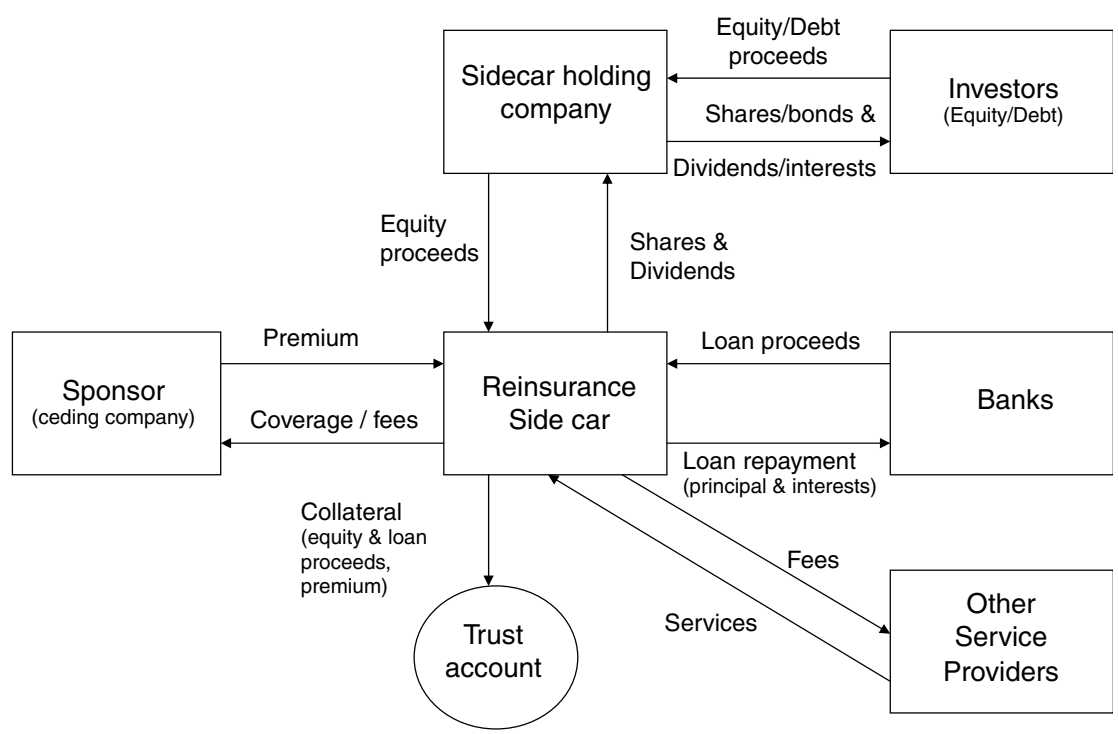

Figure 1. Sidecars - players and transactions.

sidecar's capacity their own, enabling them to expand their ability to supply coverage, especially in lines experiencing limit constraints. ${ }^{39}$ Catastrophe lines are particularly exposed to these constraints, as depletion may prove substantive and may happen over a very short period of time. A second motivation, following from the previous point, is that the sponsor's ability to supply increased capacity enables it to negotiate the provision of coverage from a position of strength. ${ }^{40}$ Third, the sponsor's condition of sole client/underwriter makes possible the addition of a stream of revenue, constituted by the commissions charged to the sidecar with respect to the services provided as the one procuring the business and delivering the underwriting. ${ }^{41}$ Moreover, many sponsors also arrange a profit commission with the sidecar. ${ }^{42}$

Looking at the phenomenon of sidecars from the perspective of the sponsor with particular reference to the sponsor's need to raise capital in order to expand capacity, rating agency Fitch $^{43}$ notes that sidecars appear to constitute a more time-efficient mechanism for sponsors as opposed to raising capital directly on their own books. Moreover, as investors invest in the sidecar and not in the sponsor, the sponsor's equity does not suffer the dilutive effect of direct capital-raising. $^{44}$

\footnotetext{
${ }^{39}$ Financial Services Authority (2007).

${ }^{40}$ Perez (2007).

${ }^{41}$ Green (2006b).

${ }^{42}$ Goldman Sachs (2006).

${ }^{43}$ Fitch (2006).

${ }^{44}$ Guy Carpenter (2006b)
} 
Last but not least, sponsors may have identified in the sidecar arrangement an alternative to their own retrocession programmes, organising via the sidecar the share of business for which coverage is sought. ${ }^{45}$

Looking at the rationale for investors' interest in sidecars, the prospect of high returns is cited as the overriding argument, in the light of increased rates for reinsurance coverage in the lines written by the sidecar. ${ }^{46}$ Sidecar investors, as holders of equity in sidecars, stand to benefit directly from the sidecar's profitability, returned to them in the form of dividends.

Second, sidecars provide a corporate arrangement that enables investors to enter into the reinsurance market in a timely manner, that is, while rates are at the high end of the cycle. ${ }^{47}$ Following this point, as arrangements with a limited purpose, sidecars appear to offer comparatively less complexity with respect to setting up and winding down a company. ${ }^{48}$

A third key element driving investors into sidecars is the possibility of benefiting from the dual role of client and underwriter performed by the sponsor. As such, sidecars can combine the benefits of a newly created company with the experience and expertise of well-established reinsurance underwriting teams. ${ }^{49}$

Fourth, sidecars as "automatic" companies face a less demanding effort, in terms of time, material and financial resources, with respect to setting up an infrastructure. ${ }^{50}$ Sidecars can be designed and set in motion within 6 weeks. ${ }^{51}$

A fifth point noted in the literature is the narrowly defined, and in particular, shortterm nature of the investments in question. ${ }^{52}$ In this respect, the risk-circumscription and time-limitations that characterise sidecars appear to be of benefit for the kind of capital market players interested in them. ${ }^{53}$

Sixth, private equity funds, and more importantly, hedge funds, have identified in sidecars an investment opportunity that contributes positively to their needs to diversify their investment portfolio. Moreover, this diversification is achieved on a type of asset, that is, the sidecar, which appears to offer additional benefits with respect to the very limited degree of correlation that it has with other financial markets assets. ${ }^{54}$

Investors also appear attracted to the ability to tailor-make the sidecar jointly with the sponsors, as opposed to the more ready-made nature of Cat bonds, for example. ${ }^{55}$ Moreover, investors in sidecars, as investors in newly formed reinsurance companies, do not face the potential problems emerging from the legacy that existing companies carry with them. ${ }^{56}$ Further, some elements that characterise the sidecar, like quota

${ }^{45}$ Lane (2007); Sclafane (2006).

${ }^{46}$ Financial Services Authority (2007); Green (2006c); Thiele (2006).

${ }^{47}$ Greenwald (2006).

${ }^{48}$ State Board Administration of Florida (2006).

${ }^{49}$ Guy Carpenter (2006b).

${ }^{50}$ Ibid., Standard and Poor's (2006).

${ }^{51}$ Perez (2007).

52 Moody's (2006).

${ }^{53}$ The Economist (2007).

${ }^{54}$ Financial Services Authority (2007); Holderness and Williams (2006).

55 Moody's (2006); Sigma (2006).

56 Moody's (2006). 
share agreements or profit commissions, are perceived by investors as acting as moral hazard deterrents. ${ }^{57}$

Summing up, our brief review of the literature on sidecars has helped us better understand what sidecars are, and the extent of the main differences with and similarities to other reinsurance companies. Although sidecars are in their simplest form an insurance company, or better said, a reinsurance company, unlike traditional reinsurers they are attached to one single client - the sponsor - by one quota share contract, covering catastrophic risks, and doing so for a limited period of time. Moreover, and probably more importantly, sidecars appear unique in allowing sponsor, investors and service providers to tailor-make the terms and conditions of the company, and to do so in an extraordinarily short period of time.

\section{Sidecars - regulatory and supervisory issues}

So far, we have described the context in which sidecars have emerged and reviewed the literature discussing the sidecars themselves. This section looks at the sidecars from the perspective of the financial services regulator. Further, we narrow the focus and discuss sidecars from the perspective of the Bermuda Monetary Authority (BMA), as the regulator of most of the existing sidecars. ${ }^{58}$

This section has been structured as follows. First, we provide a brief introduction to the BMA's regulatory and supervisory framework, with specific attention to the regulation and supervision of insurance companies. Second, we discuss the findings of an analysis of the structure and operation of the insurance companies that had a licence application approved by the BMA during the period September 2005 to December 2006. This analysis will help us test empirically some of the claims discussed in the previous section. Finally, we discuss some key issues emerging from the regulation and supervision of sidecars.

\section{BMA's framework for insurance supervision}

The BMA's principal role is as an independent licensing and supervisory regulatory body for regulated financial institutions, including insurance and reinsurance companies. ${ }^{59}$

The process for licensing and ongoing supervision is risk-based. With respect to licensing, the BMA assesses the nature, scale and complexity of the entity seeking to be based in Bermuda as well as its related risks and the level of sophistication of the clients involved; it then supervises them accordingly.

In Bermuda, entities applying to be registered (i.e. licensed) as a general business insurer (non-life) submit an application for an insurance/reinsurance licence in one of four categories. ${ }^{60}$

\footnotetext{
57 Collis (2006).
}

${ }^{58}$ Sclafane (2007).

${ }^{59}$ See Bermuda Monetary Authority Act 1969 and subsequent amendments. Laws of Bermuda are accessible at http://www.bermudalaws.bm.

${ }^{60}$ See Insurance Act 1978 and subsequent amendments. Laws of Bermuda are accessible at http:// www.bermudalaws.bm. 
- Class 1 - Single-parent captive insuring the risks of its owners or affiliates of the owners.

- Class 2 - (a) a multi-owner captive insuring the risks of its owners or affiliates of the owners, (b) a single parent and multi-owner captive: (i) insuring the risks related to or arising out of the business or operations of the owners and affiliates, and/or (ii) deriving up to 20 per cent of its net premiums from unrelated risks.

- Class 3 - Insurers and reinsurers not included in Class 1, 2 or 4, such as: Reinsurers writing third-party business; insurers writing direct policies with third-party individuals; single parent, group, association, or joint venture captives where more than 20 per cent of net premiums written arises from risks which are unrelated to the business; finite reinsurers and rent-a-captives.

- Class 4 - Insurers and reinsurers capitalised at a minimum of \$100 million underwriting excess liability and/or property catastrophe reinsurance risk.

In addition, a company seeking to do long-term business (life) is required to apply for a separate Long-Term licence.

At the licensing stage, that is, the applicant's request to be registered as a particular class of insurer, the BMA reviews the application submitted by the applicant. Key documents in the application include a Business Plan containing detailed information on the rationale for registering, ownership of the insurer, details on senior management and staff, capitalisation, types of business to be conducted, limits and net retention, and pro-forma financials on a 5-year basis showing evidence of how the minimum solvency margin and the liquidity ratio will be maintained at all times. The degree of detail and additional information required is affected by the type of licence in question, that is, Class 3 and 4 licence applications are subject to relatively more demanding scrutiny compared to Class 1 and 2 applicants for licensing.

An additional feature in Bermuda's licensing regime is that of the Principal Representative. ${ }^{61}$ Every registered insurer is required to appoint a Principal Representative that has to be approved by the BMA. Principal Representatives must be knowledgeable in insurance and are responsible for statutory filings as well as for the maintenance of and custody of the statutory accounting records. In general, Principal Representatives are a director, senior financial officer or manager of the company, or a Bermuda-registered insurance management company.

With respect to supervision of licence-holders and in line with the differential treatment at the licensing stage, Class 3 and 4 licence-holders are subjected to a more comprehensive and demanding supervisory review. This includes a regime of off-site and on-site inspection, stricter reporting deadlines, higher solvency requirements and annual certifications by qualified actuaries of technical provisions.

\section{An empirical look at sidecars}

As it transpires from the section above, the BMA supervisory framework for insurance companies, and specifically, BMA's multi-licensing system do not have definitions of,

\footnotetext{
${ }^{61}$ See Insurance Act 1978 and subsequent amendments.
} 
or dedicated provisions, for the treatment of sidecars, nor for the treatment of Special Purpose Vehicles or sponsors. In other words, "to-be sidecars" are subjected to the licensing alternatives that are in place for other commercial insurance or reinsurance companies, that is, a Class 3 or Class 4 licence. Further, as Class 3 or Class 4 licenceholders, sidecars would be subjected to the supervisory regime covering companies under these classes of licences.

In order to better understand the specific elements of the supervision of sidecars in the light of the absence of a definition of sidecar in Bermuda's legislation and regulation, all Class 3 and Class 4 applications approved ${ }^{62}$ by the BMA in the period 1 September 2005 to 31 December 2006 were tested against the defining characteristics of sidecars, as discussed in the previous section. The total population was 84 companies, 71 Class 3 licence companies and 13 Class 4 licence companies. The sources of data used for the determination of the population and for the analysis of the companies were the complete company files at the BMA. The prime source was the Business Plan submitted by applicants.

The first test checked the narrow definition of sidecar (i.e. the "true" sidecar, in A.M. Best language), that is, the existence of a single client, the sponsor. Out of the 84 companies included in the period under observation, 17 companies were writing business with one client only; where there was more than one client, the clients all belonged to the same group of companies. ${ }^{63}$

A second, broader, test widened the definition of sidecar. It included two additional types of companies. The first type were companies operating primarily with one client (i.e. at least two-thirds of all gross written premiums). The second type were companies writing third-party business that fully "mirrored" the business written by another reinsurer. In other words, these companies were quota-sharing business with another reinsurer, but doing so under two "mirror" contracts, as opposed to one contract only. This second test, which included the "market facing" sidecars discussed in the previous section, yielded a total of nine companies. In short, during the period under observation, out of 84 companies, 26 fall under the category of a sidecar, 17 being so under the narrow definition (the "true" sidecar) and nine "market facing" sidecars. Importantly, in none of these cases were companies selling coverage directly. All 26 companies had either insurers or reinsurers as clients, empirically restricting the notion of the sidecar to the reinsurance or retrocessional markets only.

A third test looked at the financing of the sidecar and the extent to which high-risk appetite financiers were the funders of the undertaking. In this respect, all 26 companies were found to be financed by a mix of private equity, hedge funds and investment banks, in line with the findings from the literature review.

Looking at the role of the players in the structuring of the company, data from the 26 companies mentioned above seems to show greater diversity on the role of the sponsor. While it appears to be the case that in most companies the driving force behind the undertaking was the client, in other companies, the sponsoring role appears

\footnotetext{
${ }^{62}$ We also treated as "approved" those already existing licences that underwent substantial changes during the period under observation (e.g. licences that changed ownership).

${ }^{63}$ This includes Lloyds syndicates.
} 
shared between client and investor, or between the client and a client's intermediary. Moreover, some companies appeared sponsored by the investors, with the client having a less active role.

Analysing the business written by the 26 companies under observation, the findings confirm what was discussed in the literature review. First, the duration of contracts did not exceed 36 months. Second, the location of the risks covered was mostly the United States of America. Third, the type of reinsurance or retrocession contract entered into was a quota-share agreement, although this was not exclusively the case (i.e. examples were found of excess of loss contracts). Fourth, the risks covered were mainly property catastrophe risk. Finally, with respect to the terms of the ceding arrangements regarding the limits of liability accepted by the company, the 26 cases under observation were consistent with the literature review in that in the majority of cases liability was set at an aggregate limit and in some cases calculated at a multiple of the probable maximum loss (PML) or to a loss ratio cap.

With respect to the extent of the use of collateralisation, all 26 companies were found to be engaged in some form of collateralisation arrangement oriented to provide additional assurance to the cedent that, should a claims-generating event take place, the company would have funds to cover the liabilities assumed. In line with what was discussed in the previous sections, the determination of the funds to be held as collateral followed the terms agreed in the ceding arrangements (i.e. aggregate limit, PML multiple or loss ratio cap). Moreover, while most of the above-mentioned collateral takes the form of a trust deposit where capital, surplus and premiums are deposited, a minority of companies opted for Letters of Credit issued by NAICrecognised banks to produce the necessary guarantees; some companies opted for mixtures of the above.

Regarding the operation of the companies in our sample, the empirical data shows correspondence with the literature review. Indeed, we found that all 26 companies relied on full outsourcing of services.

Finally, we looked at the amount of capital involved in the 26 companies under observation. Data from the financial projections incorporated in the companies' business plans showed a total projected funding of USD 6.4 billion to end-2006, including equity and loans, and excluding premiums. This figure goes down to USD 4.9 billion, if we consider just the 17 "true" sidecars. To put these data in context, sidecars appear to have contributed to approximately 17 per cent of capital raised after the U.S.A. 2005 hurricane season; existing reinsurers contributed 31 per cent, new start-ups, 23 per cent and Cat bonds and Insurance Linked Securities 16 per cent. ${ }^{64}$

\section{Regulatory and supervisory issues related to sidecars}

This section looks at key elements regarding the regulation and supervision of the companies described in the section above. As we have shown, all companies appeared engaged in reinsurance rather than direct insurance. Moreover, most companies provide reinsurance coverage to reinsurers, that is, retrocessional coverage. In the light

\footnotetext{
64 Lane (2007).
} 
of these findings we have arranged this section on regulation and supervision following the framework set by the International Association of Insurance Supervisors (IAIS) in the IAIS Principles on Minimum Requirements for the Supervision of Reinsurers ${ }^{65}$ and the IAIS Insurance Core Principles. ${ }^{66}$ In particular, we focus on those elements that are specific to the companies reviewed, that is, the relation between the cedent and the company, the relation between the company and the investors, the relation between cedent, company and investors, and issues pertaining to the company as such, and to its relations with other third parties.

Issues of concern for insurance supervisors with respect to the relation between cedent and company, touch mainly on the following: (1) the provision of underwriting expertise by the cedent to the company, and (2) the characteristics of the arrangements enabling the transfer of risk from the cedent to the company.

As discussed above, companies rely on the underwriting expertise provided by the cedent, as they do not have in-house underwriting resources. This aspect demands specific scrutiny, commencing at the licence application stage. In particular, applicants bear the onus of satisfying the supervisor, among other things, that underwriting services will be provided by a team with high-quality track record of experience in the business, and that models, systems and procedures are in place for the underwriting team to carry out its duties in a suitable manner. Names of members of the underwriting team, copies of their curriculum vitae, details of models, systems and procedures can help supervisors get an understanding of the soundness of underwriting in the company. Within the Bermuda framework, these precautions should be understood as operating in conjunction with the ones discussed above in the section on the BMA, including those relating to the Principal Representative.

Regarding the contractual arrangements for risk transfer from the cedent to the company, elements that are of special interest to the supervisor include: the terms under which risks are shared between cedent and company, if the transfer is done under a quota share arrangement; the provisions in place for the quantification of the risk transferred (e.g. aggregate limit, PML, loss ratio, etc.); and any provisions regarding the cession of risks retained by the cedent. Regarding the latter point, clarity appears paramount with respect to the obligations assumed by the cedent vis-à-vis the company in relation to the cedent transferring its share of the risk to third parties. Key for the supervisory scrutiny of the risk transfer contractual arrangements between cedent and company is the provision of copies of the contracts.

Finally, and with specific regard to the sample of companies discussed in the sections above, nearly all cedents are in turn Bermuda-based insurance licence holders. This element facilitates the understanding of, and comfort with the cedent by the supervisors, in particular given the pivotal role played by cedents in sidecars, as has been repeatedly demonstrated in the paper. Moreover, the knowledge, expertise and general track record of the cedent by the supervisor adds to the relationship between cedent and company within the programme of on-site inspection of the cedent.

\footnotetext{
${ }^{65}$ International Association of Insurance Supervisors (2002).

${ }^{66}$ International Association of Insurance Supervisors (2003).
} 
With respect to the relation between the company and the investors, issues that appear of specific concern for supervisors include: the information provided to investors at the funding stages, the relevant knowledge and understanding of insurance business demonstrated by the investors, and the constraints with respect to disinvesting in the company.

The first element with respect to the relation between the investors and the company is the information provided to investors at the funding stages. Important here is the detail and clarity with which the risks inherent in the investment venture are communicated to investors, in particular, risks related to the volatility of the reinsurance business and to the possibility of investors losing up to the full amount of the monies invested. Copies of prospectuses allow the supervisor to determine the extent to which this issue appears adequately addressed.

Although, as mentioned in the sections above, investors taking part in the financing of the companies studied are not lay investors, the issue of the extent to which these institutional or sophisticated or qualified players are in a position to adequately grasp the risks inherent to reinsurance transactions is of interest to supervisors. Investors need to understand the risks, and especially volatility, involved in reinsurance operations; they need to demonstrate that they possess the knowledge and skills that are necessary to negotiate complex reinsurance contracts (e.g. quota share agreements) with a unique counter-party (i.e. a cedent that is also the company's underwriter).

In this respect, documentation demonstrating knowledge and expertise in reinsurance business to be submitted by investors to the supervisor at the licence application stage appears crucial. This can take the form of corporate documents, key staff curriculum vitae, examples of previous similar transactions, etc. Further, documentation demonstrating knowledge of and expertise in the business generating the demand for reinsurance coverage adds a further layer of clarity (e.g. an investment fund with a track record of investment in offshore energy infrastructure intending to finance energy catastrophe reinsurance coverage). In addition, partnership arrangements between investors and insurance brokers or consultants can help satisfy the supervisor that prudential measures have been activated in order to ensure that investors gain awareness of the insurance business. Copies of the partnership arrangements submitted to the supervisor provide an additional layer of clarity.

Last but not least there is the issue of the understanding by the investors and by the supervisor of restrictions on share repurchase by the company as well as the articulation of these restrictions in the various arrangements in support of the financing of the company. This element is closely related to the two points mentioned above, as it entails an understanding of the timing of reinsurance contracts and the provision of reinsurance coverage. Again, copies of prospectuses permit supervisors to assess the extent to which these elements have been addressed at the licence application stage. Very importantly, as share repurchase may be related to the reinsurance risk being transferred back to the cedent, the supervisor needs to be satisfied that sound provisions are in place to determine, among other things, the terms of this risk transfer, the bearers of the risk at any given time, and the amount of capital available in support of the risk borne. As mentioned above, in the Bermuda case, the monitoring and supervision of risk transfer appears facilitated by cedent and company being Bermuda-based licence-holders. 
Finally, as with the case of the cedents, many of the investors funding Bermudabased companies are - or have been - investors in other Bermuda-based insurance companies, hence are known to the supervisor. Moreover, some of these investors are themselves Bermuda-based, and as such, subjected to supervision by the BMA.

A third area of issues of concern for supervisors is that of the relationship between the cedent, the company and the investors. Here the focus is turned on to the arrangements in place for the collateralisation of the risks taken by the company. Cedents, it should be reminded, are the bearers of the risk in relation to the primary insurer, as such they are ultimately liable for these; it is crucial for cedents that sufficient precautions are in place in order to minimise the possibility that the company fails to meet its liabilities for the risks assumed. The design and documentation of the collateralisation arrangements play a critical role in enabling the cedent to manage the quota of risk ceded to the company. Important elements in the collateralisation include: the uses of trust accounts, letters of credits, guarantees or combinations of them; the soundness of the institutions - in addition to investors, cedent and company - taking part in the arrangement (e.g. banks); the various flows of monies in and out of the collateral account (e.g. proceeds of paid up equity, loan disbursements, premiums, etc. and, on the other hand, commissions, fees, claims, etc.); the conditions attached to the movement of monies in and out of the collateral account; the procedures for determination of the minimum balance to be held at the collateral; and, the relation between the minimum balance and actual exposure of the company. As with the previous issues discussed above, the submission to the supervisor of contractual documentation demonstrating the soundness of the collateralisation arrangements in place can provide clarity in the licensing and supervision process.

Last but not least, we look at issues of interest to supervisors and pertaining to the company as such and to its relations with other third parties. As mentioned repeatedly in the paper, so-called sidecars rely on a network of arrangements and relations to come to life and to operate. As such, understanding the full constellation of relationships, in additions to those described above, is critical. Of special interest to the supervisor are the following: the appointment by the company of a Loss Reserve Specialist, which in the case of Bermuda has to be approved by the BMA; and the contracting of services including company management, claims management, investment management, legal counsel and auditor services. In all these arrangements, clarity is sought with respect to the track record and experience of service providers, the terms of the contracts (e.g. length of contracts, remuneration systems and levels, etc.), the various reporting arrangements among the players, and the documentation in support of these contracts.

Finally, we look at issues that pertain to the company as such, for example business strategy, business horizon, investment strategy, etc. Understanding the soundness and consistency of these elements is paramount and it may be done in practice via analysis of the company's business plan, financial projections and additional documentation as well as face-to-face meeting with key players.

We conclude this section by pointing out that a likely outcome of the supervisory scrutiny of the issues discussed above is the issuance of restricted licences. Companies may be granted a licence, although this is issued with restrictions attached. Based on a case-by-case analysis, restrictions may affect one or more of the following: the number of clients the company will be entitled to sell coverage to, the number of reinsurance 
contracts the company will be allowed to enter into, the minimum level of collateral the company will be requested to keep, and the kind of documentation the company will be requested to submit with respect to the state of the collateral arrangement.

\section{Concluding remarks}

Our exploration of sidecars has taken us through the various market events that set the scene for their emergence, the building blocks and forces shaping sidecars and the key challenges faced by insurance supervisors. Let us now step back and look at the phenomenon of sidecars in the context of globalised financial markets.

First, sidecars have timely assisted the supply-demand gap experienced by the reinsurance sector by facilitating inflows of funds from the capital markets. However, further research is needed to better understand whether sidecars have contributed to counteracting the insurance cycle. As the first signs of softening of the insurance cycle emerge, sidecars begin to retreat, their shares repurchased, their loans paid back or the entire company wound up. ${ }^{67}$ In this respect, sidecars have acted, according to Moody's, as "rapid response" reinsurance. ${ }^{68}$ However, it should be noted that the robustness of sidecars was not tested against the occurrence of the events that created them, that is, severe windstorms or other catastrophes. In other words, sidecars remain in their "infancy."

Second, the phenomenon of sidecars can be framed in the context of the upward trend of non-traditional cross-sectoral risk transfer. ${ }^{70}$ Although, as we have seen, sidecars contributed a small amount to the flows of cross-sectoral risk transfer, the concept of sidecar succeeded in gaining a place among the solutions created by the financial markets to interact with each other. ${ }^{71}$ Importantly, sidecars appear in a unique position to facilitate the involvement of the capital markets in the retrocession market, to expand capacity, and to do so via spreading insurance risk across sectors. ${ }^{72}$ Concerns about the reinsurance sector's potential for systemic risk have been analysed and have proved not to be founded. ${ }^{73}$ Sidecars can act as a positive contribution to further strengthening these findings.

Finally, our journey into sidecars has also helped better understand the relation between the insurance industry and insurance supervisors with respect to market innovation. As shown, the success of sidecars hinges, among other things, on the issue of time. The ability of a variety of different players to get together and tailor-make and license a company that is acceptable to all parties, and does so in a very short period of time, must not be underestimated. Sidecars are a genuine example of innovation in contemporary financial markets, that is, markets in constant process of convergence,

\footnotetext{
${ }^{67}$ Benfield (2007); Ceniceros (2007); Sclafane (2007); The Insurance Insider (2007).

68 Moody's (2006).

${ }^{69}$ Financial Services Authority (2007).

${ }^{70}$ Groome et al. (2006).

${ }^{71}$ In this respect, it is important to note that although the word sidecar was coined in 2005 , the concept is not new (IAIS (2006)). Sidecar-like arrangements or "first generation" sidecars (Green (2006b)) can be traced back in Bermuda to the late 1990s (Goldman Sachs (2006)).

${ }^{72}$ Lane (2007).

${ }^{73}$ Group of Thirty (2006); Sigma (2003).
} 
where boundaries are increasingly blurred, and where functioning is made more dynamic via the introduction of new technologies. ${ }^{74}$ Studying the performance of Bermuda-based insurance companies in the mid-1990s, Adams and Buckle ${ }^{75}$ concluded that Bermuda's licensing strategy was "correct to encourage an open market for new entrants." Ten years on, looking at sidecars in particular and at the strength and performance of Bermuda insurance market in general, this appears to continue to be the case.

\section{References}

Adams, M. and Buckle, M. (2003) 'The determinants of corporate financial performance in the Bermuda insurance market', Applied Financial Economics 13: 133-143.

Adkisson, J. (2006) Captive Insurance Companies: An Introduction to Captives, Closely-Held Insurance Companies, and Risk Retention Groups, Lincoln, NE: iUniverse Incorporated.

A.M. Best (2006a) 2006 Global Reinsurance Report (August).

A.M. Best (2006b) Assessing the "Tail Risk" of Sidecars (October).

Benfield (2006a) Reinsurance Market and Renewals Review (January).

Benfield (2006b) Sidecars: Chariots for Hire (Autumn).

Benfield (2007) Benfield Bermuda Quarterly FY2006: Capital Returns (March).

Caruana, J. (2005) 'Is supervision keeping pace with innovation?', The Geneva Papers on Risk and Insurance-Issues and Practice 30: 11-18.

Ceniceros, R. (2007) 'Sidecar participation is receding', Business Insurance, 12 March.

Collis, C. (2006) 'Sidecars - An Alternative to Cat Bonds', from http://www.conyersdillandpearman.com, accessed 10 July 2006.

Enz, R. (2002) The Insurance Cycle as an Entrepreneurial Challenge, Zurich: Swiss Re Technical Publishing. Financial Services Authority (2002) Cross-sector risk transfers, FSA Discussion Papers Series (May), The Financial Services Authority, London, UK, from http://www.fsa.gov.uk, accessed 9 August 2006.

Financial Services Authority (2007) Financial Risk Outlook (January).

Fitch (2006) Reinsurance Review and Outlook: Cycle Management - A Bumpy Ride Ahead (September).

Goldman Sachs (2006) Presentation Regarding the Transfer of Catastrophe Risk to the Capital Markets, presentation to the Florida Property and Casualty insurance Reform Committee, 24 August.

Green, M. (2006a) 'Private equity eyes insurance', Best Review 107(2): 43-46.

Green, M. (2006b) 'New ventures, new vehicles', Best Review 107(1): 54-56.

Green, M. (2006c) 'More risk, more reward', Best Review 107(3): 61-65.

Greenwald, J. (2006) 'Sidecars gaining traction with the help of capital markets', Business Insurance 17 July.

Groome, T., Blancher, N., Haas, F., Kiff, J., Lee, W., Mills, P., Nakagawa, S., Ramlogan, P., Khadarina, O. and Kim, Y. (2006) The limits of market-based risk transfer and implications for managing systemic risks, Working paper, IMF, Washington, DC.

Group of Thirty (2006) 'Reinsurance and International Financial Markets', from http://www.group30.org, accessed 15 January 2006.

Guy Carpenter (2005) The Growing Appetite for Catastrophe Risk: The Catastrophe Bond Market at Year-End 2004, New York.

Guy Carpenter (2006a) Rating Agency Update: Stepping up to New Criteria (November).

Guy Carpenter (2006b) Bermuda reinsurance market: After Record Storms, Capital Fills Sails, New York.

Guy Carpenter (2006c) U.S. Reinsurance Renewals Divergent Paths after Record Storms, New York.

Guy Carpenter (2007) The Catastrophe Bond Market at Year-End 2006: Ripples Into Waves, New York.

Hertz, S. and McGuiness, T. (2006) 'Sidecars: New Vehicles for Private Equity and Hedge Fund Investment in the Insurance Market, the Debevoise \& Plimpton Private Equity Report', from http://www. debevoise.com, accessed 15 February 2007.

\footnotetext{
${ }^{74}$ PricewaterhouseCoopers (2005).

75 Adams and Buckle (2003).
} 
Holderness, A. and Williams, D. (2006) 'Vehicles for success', The Lawyer, 23 October.

Horner, N. (2006) 'Why hedge funds are investing in the bermudian market', Global Legal Review, 2 October. International Association of Insurance Supervisors (2002) IAIS Principles on Minimum Requirements for the Supervision of Reinsurers (October).

International Association of Insurance Supervisors (2003) IAIS Insurance Core Principles and Methodology (October).

International Association of Insurance Supervisors (2006) Global Reinsurance Market Report (November).

Lane, M. (2006) 'What Katrina Hath Wrought', from http://www.lanefinancialllc.com, accessed 12 July 2006.

Lane, M. (2007) 'Recapitalizing Reinsurers: A Never Ending Story?', from http://www.lanefinancialllc.com, accessed 15 February 2006.

Moody's (2006) 'Reinsurance Side-Cars: Going Along for the Ride', Moody's Investors Service Global Credit Research Special Comment (April).

Perez, A. (2007) Reinsurance Sidecars, paper presented to the Bermuda Insurance Institute, 8 March.

PricewaterhouseCoopers (2005) Piecing the Jigsaw: The Future of Financial Services, from http:// www.pwc.com, accessed 30 August 2005.

Risk Management Solutions (2005) Hurricane Katrina: Profile of a Super CAT-Lessons and Implications for Catastrophe Risk Management (August).

Sclafane, S. (2006) 'U.S. reinsurance report: Cat Re capacity shrinks for key regions', National Underwriter, Property \& Casualty, 17 July.

Sclafane, S. (2007) 'Is the sidecar joyride over?' National Underwriter, Property \& Casualty, 19 February.

Sigma (2003) Reinsurance - A Systemic Risk?, Number 5/2003.

Sigma (2006) Securitization - New Opportunities for Insurers and Investors, Number 7/2006.

Standard and Poor's (2006) Global Reinsurance Highlights, London: Reactions Publishing Group.

State Board Administration of Florida (2006) A Study of Private Capital Investment Options and Capital Formation Impacting Florida's Residential Insurance Market (September).

Terzo, G. (2006) 'Sidecars gain traction', Investment Dealer's Digest, December 25.

The Economist (2007) Hedge Funds Find a New Way to Profit by Taking on the Weather Gods (10 February). The Insurance Insider (2007) Sidecars Left to Rust, London: Insider Publishing Limited, (9 March).

Thiele, P. (2006) The Bermuda Market: A Historical Perspective, presented at Fox-Pit Kelton, Boston, MA, 19 September.

Wharton Risk Center (2007) Managing Large-Scale Risks in a New Era of Catastrophes, Report on Phase I of the Study, Wharton Risk Center Extreme Events Project, Philadelphia.

\section{About the authors}

Marcelo Ramella is Assistant Director Research at the Bermuda Monetary Authority and Visiting Fellow at the UK London School of Economics and Political Science (LSE). He has a long-standing research interest in innovative practices, especially processes of social and institutional legitimation of innovation. A National Public Accountant (Buenos Aires, Argentina), he has an MBA from Bocconi University (Milan, Italy), and an MSc in Social and Organisational Psychology and PhD in Social Psychology from the LSE.

Leila Madeiros is Assistant Director and Corporate Secretary of the Association of Bermuda Insurers and Reinsurers (ABIR), a professional trade association representing Bermuda's Class 4 insurers and reinsurers. Formerly, she was Deputy Director of Policy, Research and Communications at the Bermuda Monetary Authority, and previously, an insurance supervisor and regulator with the Registrar of Companies Department. She holds an MA in Management from Webster University (Missouri, U.S.A.) and BA in Business Administration from Cedarville University (Ohio, U.S.A.). 